\title{
Note on Contranano Semipre Continuous Functions
}

\author{
K. Rajalakshmi', C. Vignesh Kumar ${ }^{2}$, V. Rajendran ${ }^{2}$ and P. Sathishmohan ${ }^{2}$ \\ 'Science and Humanities, Sri Krishna College of Engineering and Technology, Competency-based Education-08, \\ Coimbatore-641008, Tamil Nadu, India; rajalakshmikandasamy@gmail.com \\ ${ }^{2}$ Department of Mathematics, Kongunadu Arts and Science College, Coimbatore - 641029, Tamil Nadu, India; \\ vigneshkumarcvk@gmail.com, rajendrankasc@gmail.com, iiscsathish@yahoo.co.in
}

\begin{abstract}
This study is devoted to introducing and also it looks into the properties of nano semipre-cont, nano semipre-open funcs, nano semipre-closed funcs, Contranano semiprecont.funcs and obtains some relationship between the existing sets.
\end{abstract}

Keywords: Almost N $\beta$-cont, Contranano $\beta$-cont, Nano $\beta$-cont, Nano $\beta$-closed, Nano $\beta$-open, NP- $\beta$-open, N $\beta$-regular

\section{Introduction and Preliminaries}

$\mathrm{In}^{1}$ introduced generalized closed sets in topological spaces. The notion of Nano topology was introduced by ${ }^{2}$. The basic definitions are referred from the following study $\stackrel{2-9}{ }$. Throughout this study, func represents the function, image as ima, continuous as cont, inverses as invrs.

\section{Nano Semiprecont, Nano semipreopen and Nano semipreclosed Funcs}

In this section, we study some additional properties of $\mathrm{N} \beta$-cont.func, $\mathrm{N} \beta$-open and $\mathrm{N} \beta$-closed funcs.

Definition 2.1. A func $\mathrm{k}$ is called $\mathrm{N} \beta$-open if the ima of each nano open set $A$ of $U$ is $N \beta$-open in $V$.

Definition 2.2. A func is called $N \beta$-closed if the ima of nano closed set $\mathrm{A}$ of $\mathrm{U}$ is $\mathrm{N} \beta$-closed in $\mathrm{V}$.

Theorem 2.2. Let be a N $\beta$-contand $\mathrm{Na}$-open func then the invrsima of each nano open set in $\mathrm{V}$ is $\mathrm{N} \beta$-open in $\mathrm{U}$.

Theorem 2.3. Let be a $\mathrm{N} \beta$-contand nano open mapping then the following statements hold. (a) The invrsima of each NP-open set in V is N $\beta$-open in $\mathrm{U}$

(b) The invrsima of each NS-open set in V is N $\beta$-open in $\mathrm{U}$

Theorem 2.4. Let be bijective $\mathrm{N} \beta$-contand $\mathrm{l}: \mathrm{V} \rightarrow \mathrm{W}$ be bijectivenanocont.funcs then lok: $\mathrm{U} \rightarrow \mathrm{W}$ is $\mathrm{N} \beta$-cont. func.

Prook: Let $\mathrm{V}$ be any nano open subset of $\mathrm{Z}$ then $\mathrm{l}^{-1}(\mathrm{~V})$ benano open in $\mathrm{Y}$ and as $\mathrm{f}$ is $\mathrm{N} \beta$ - $\operatorname{contk}^{-1}\left(\mathrm{l}^{-1}(\mathrm{~V})\right)$ is $\mathrm{N} \beta$-open in $\mathrm{X}$ i.e., $(\mathrm{lok})^{-1}(\mathrm{~V})$ is $\mathrm{N} \beta$ - open in $\mathrm{X}$ implies lok is $\mathrm{N} \beta$-cont.func.

Theorem 2.5. Each NS-open (NP-open) func is N $\beta$-open but not conversely.

Let $\mathrm{k}: \mathrm{U} \rightarrow \mathrm{V}$ be NS-open (NP-open) and A be any nano open subset of $\mathrm{U}$ then (A) is NS-open (NP-open) in $\mathrm{Y}$, as every NS-open (NP-open) set is $\mathrm{N} \beta$-open, $\mathrm{k}(\mathrm{A})$ is $\mathrm{N} \beta$-open in $X$. Hence $f$ is $N \beta$-open function.

Theorem 2.6. A bijectivefunc is $\mathrm{N} \beta$-open iff it is $\mathrm{N} \beta$-closed. Theorem 2.7. Let $\mathrm{k}: \mathrm{U} \rightarrow \mathrm{V}$ be bijective $\mathrm{N} \beta$-open (N $\beta$-closed) func. $\mathrm{W} \subset \mathrm{V}$ and $\mathrm{F} \subset \mathrm{U}$ is a nanoclosed(nanoopen) set containing $\mathrm{k}^{-1}(\mathrm{~W})$ then $\mathrm{N} \beta$-closed (N $\beta$-open) set $\mathrm{H}$ of $\mathrm{V}$ containing $\mathrm{W}$ such that $\mathrm{k}^{-1}(\mathrm{H}) \subset \mathrm{F}$. 


\section{Contranano Semipre Contfunctions}

In this section, we study a new class of func s called Contranano semi pre cont. funcs and its related properties.

Definition 3.1. A funck: $U \rightarrow V$ is called Contranano semi pre (or Contranano- $\beta$ ) cont. func if the invrsima of each nano open set of $\mathrm{V}$ is $\mathrm{N} \beta$-closed set in $\mathrm{U}$.

Definition 3.2. A funck: $U \rightarrow$ Vis called nano almost $\beta$-cont, if the invrsima of each $\mathrm{NRO}(\mathrm{U}, \mathrm{X}) \mathrm{A}$ of a space $\left(\mathrm{V}, \tau_{\mathrm{R}}{ }^{\prime}(\mathrm{Y})\right)$ is $\mathrm{N} \beta \mathrm{O}(\mathrm{U}, \mathrm{X})$ in $\left(\mathrm{U}, \tau_{\mathrm{R}}(\mathrm{X})\right)$ and it is denoted by almost $\mathrm{N} \beta$-cont.

Definition 3.2. A funck: $U \rightarrow$ Vis said to be nano presemipre (or NP $\beta$ ) open if the $f(B)$ is $N \beta$-open in $V$ for eachN $\beta$-open set B in $U$.

Definition 3.3. A subset $A$ of $U$ is said to be nano semipre regular, if it is both $N \beta$-open and $N \beta$-closed set and set of all $N \beta$ regular sets of $U$ is denoted by $N \beta R(U)$.

Lemma 3.5. In aNTSU, $\mathrm{N} \beta \mathrm{cl}(\mathrm{A}) \subset \mathrm{Npcl}(\mathrm{A}) \cap \mathrm{Nscl}(\mathrm{A})$ and hence we have $\mathrm{N} \beta \mathrm{cl}(\mathrm{A}) \subset \mathrm{Npcl}(\mathrm{A}), \mathrm{N} \beta \mathrm{cl}(\mathrm{A}) \subset \mathrm{Nscl}(\mathrm{A})$.

Lemma 3.6. EachN $\beta$-open and Na-closed is nano-closed and $\mathrm{N} \beta$-closed and $\mathrm{Na}$-open is nano-open.

Lemma 3.7. A funck: $U \rightarrow V$ is nano open and nanocont then for any nano open subset $A$ of $U$ then i) $f(\operatorname{Nint}(A)$ ) $\subset \operatorname{Nintf}(A)$ ii) $\mathrm{f}(\operatorname{Ncl}(\mathrm{A}))=\operatorname{Ncl}(\mathrm{f}(\mathrm{A}))$.

Theorem 3.8. If a funck: $U \rightarrow V$ is $N P-\beta$-open, contra $\mathrm{N} \beta$-cont and $\mathrm{V}$ is nano extremely disconnected then $\mathrm{f}$ is Almost $\mathrm{N} \beta$-cont.

Theorem 3.9. The set of all points $x$ of $U$ at which $k$ : $U$ $\rightarrow \mathrm{V}$ is not contraN $\beta$-cont is identical with the union of the $N \beta$ frontier of the invrsimas of nanoclosed sets of $V$ containing $\mathrm{f}(\mathrm{x})$.

Theorem 3.10. If a funck: $\mathrm{U} \rightarrow \mathrm{V}$ is Nacontand contra $\mathrm{N} \beta$-contthen $\mathrm{f}$ is nanocont.

Theorem 3.11. If a funck: $\mathrm{U} \rightarrow \mathrm{Vis} \mathrm{Na-open}$ and contranano $\beta$-open func then $\mathrm{f}$ is nano openfunc.

Theorem 3.12. If a funck: $\mathrm{U} \rightarrow \mathrm{V}$ is Naclosed and contranano $\beta$ closed func then $\mathrm{f}$ is nanoclosedfunc.

Theorem 3.12. If a funck: $U \rightarrow V$ Contranano $\beta$-open, 1 : $\mathrm{V} \rightarrow \mathrm{W}$ is NP- $\beta$-closed then lok: $\mathrm{U} \rightarrow \mathrm{W}$ is contranano pre-open func.

Theorem 3.13. A subset of $U$ in nano topological space $U$ be $N \beta$ regular then a funck: $U \rightarrow V$ is contraN $\beta$-contif and only if $\mathrm{f}$ is $\mathrm{N} \beta$-cont.
Proof: Let a subset of $U$ be $N \beta$ regular and let $k: U \rightarrow$ Vbe contra $N \beta$-cont then for each nano open set $A$ of $V$, $\mathrm{k}^{-1}(\mathrm{~A})$ is $\mathrm{N} \beta$-closed in $U$ and hence it is $N \beta$-open as it is $\mathrm{N} \beta$ regular. Thus, invrsima of nano open set is $\mathrm{N} \beta$-open implies $\mathrm{f}$ is $\mathrm{N} \beta$ cont.

Conversely: Let a subset of $\mathrm{U}$ be $\mathrm{N} \beta$ regular and let $\mathrm{k}$ : $\mathrm{U} \rightarrow$ Vbe $\mathrm{N} \beta$-contthen for each nano open set $\mathrm{A}$ of $\mathrm{V}$, $\mathrm{k}^{-1}(\mathrm{~A})$ is $\mathrm{N} \beta$ - open in $\mathrm{U}$ and hence it is $N \beta$-closed as it is $\mathrm{N} \beta$ regular. Thus, invrsima of nano open set is $N \beta$-closed implies $\mathrm{f}$ is $\mathrm{N} \beta$-cont.

Theorem 3.15. Each Contrananosemicont (contranano pre-cont) func is $\mathrm{N} \beta$-cont.

But converse of the above theorem need not be true in general.

Theorem 3.16. If the space $U$ is nanoextremally disconnected, then each contra $\mathrm{N} \beta$-cont. func is contranano pre-cont.

Lemma 3.17. Let $A$ be a subset of a nano topological space $\mathrm{U}$. Then each $\mathrm{N} \beta$-open ( $\mathrm{N} \beta$-closed) set is nano semi-open ((nano semi-closed) if Nint $(\mathrm{Ncl}(\mathrm{A})) \subset \mathrm{Ncl}(\operatorname{Nint}(\mathrm{A}))$.

\section{Conclusion}

The properties of nano semiprecont, nano semipreopenfuncs, nano semipre closed funcs, Contranano semiprecont.funcs are investigated.

\section{References}

1. Levine N. Generalized closed sets in topology. Rendiconti del Circolo Matematico di Palermo. 1970; 19(1):89-96. https://doi.org/10.1007/BF02843888

2. Thivagar ML, Richard C. On nano forms of weekly open sets. International Journal of Mathematics and Statistics Invention (IJMSI). 2013; 1(1):31-7.

3. On New Class of Contra Continuity in Nano Topology. Available from: https://www.researchgate. net/profile/Saeid_Jafari3/publication/315892547_On_ new_class_of_contra_continuity_in_nano_topology/ links/590dadad4585159781859589/On-new-class-of-contracontinuity-in-nano-topology.pdf. Date accessed: 2016.

4. Khalaf MM, Nimer KN. Nano PS - open sets and Nano PS - continuity. International Journal of Contemporary Mathematical Sciences. 2015; 10(1):1-11. https://doi. org/10.12988/ijcms.2015.4545 
5. Theoretical Aspects of Reasoning about Data. Available from: https://www.springer.com/in/book/9780792314721. Date accessed: 1991.

6. Revathy A, Illango G. On nano $\beta$-open sets. International Journal of Contemporary Mathematical Sciences. 2015; 1(2):1-6.

7. Sathishmohan P, Rajendran V, Devika A, Vani R. On nano semi-continuity and nanoprecontinuity. International Journal of Advanced Research. 2017; 3(2):76-9.
8. Sathishmohan P, Rajendran V, Dhanasekaran PK, Vignesh Kumar C. More on preneighbourhoods in NTS. Journal of Applied Science and Computations. 2018; 5(10):899-907.

9. Sathishmohan P, Rajendran V, Vignesh Kumar C, Dhanasekaran PK. On nano semipreneighbourhoods on NTS. Malaya Journal of Mathematik. 2018; 6(1):294-8. https://doi.org/10.26637/MJM0601/0034 